\title{
MEMORIAL
}

\section{J. JOHN SEPKOSKI, JR.: A PERSONAL REFLECTION}

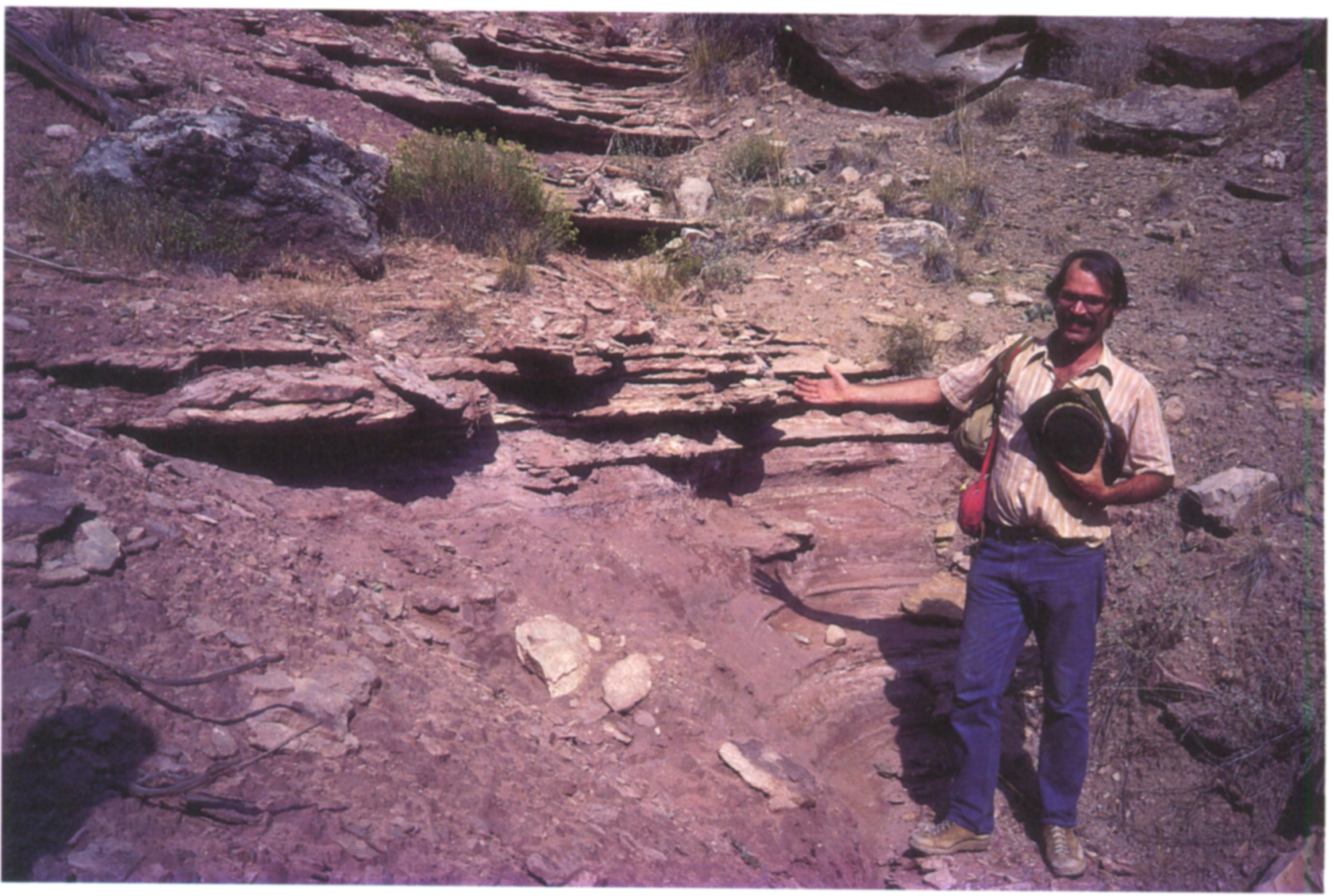

Last spring, the entire profession was shocked to hear the news that Jack Sepkoski had died at age 50. A detailed account of Jack's research career, including a full list of his publications, has been prepared by David M. Raup and can be found in the Summer, 1999 issue of Paleobiology. Rather than duplicating that effort, what follows here is a more personal perspective from one of his students.

I first met Jack in 1976, when I was an undergraduate at the University of Rochester, enrolled in his course on computer applications to geology. At the time, I was an editor of the daily student newspaper and did not spend much time on schoolwork, so it came as no surprise to me when I pulled a terrible grade on Jack's midterm. Still, the combination of Jack's course and Dave Raup's class in paleontology, which I also took that semester, really piqued my interest for the first time at Rochester in something other than the newspaper. So I felt compelled to go see Jack, to try to explain to him that I was not the blithering idiot suggested by my midterm grade. In retrospect, it was a meeting that changed my life, and it established a pattern of interaction that was maintained for the next $22+$ years. From that first day, Jack provided invaluable scientific feedback -in this initial case, with respect to some horrible answers to exam questions-but he was also genuinely interested in my personal well-being and prospects for success. Over the years that followed, I was always grateful for Jack's paleontological insights, but I was even more appreciative of his willingness to spend time talking about things that had nothing to do with science. Jack sought to reassure me on many occasions, even fairly recently, that everyone has their own demons and self-doubts to fight if they are to be successful, and he helped me to fight mine.

At Rochester, and especially at Chicago, where he moved in 1978 , Jack provided me with a box seat to some of the most exciting paleobiological research imaginable, during what might appropriately be described as a succession of epochs in the history of the science. Jack was a participant in the later stages of the computer-based, stochastic simulation of evolution ("MBL") epoch. By the time he left Rochester, he had initiated the kinetic model epoch (some of the graduate students at Rochester reported 
that, almost as a mantra, Jack would say, "I can explain all of Phanerozoic diversification with the logistic equation!"). The Three Faunas epoch dawned in 1981-the same year that I arrived in Chicago-and this was followed in quick succession by the onshore-offshore and periodicity epochs. Remarkably, Jack achieved all this before his $35^{\text {th }}$ birthday.

Through it all, Jack exuded a level of creativity, exuberance, and perseverance that is almost indescribable. His now legendary compilations of global taxonomic compendia, and the analyses that he and others generated from these data are obviously his greatest legacies to the field. But what I got from Jack went far beyond that: I got to watch him in action, and the lessons he provided by just doing his thing from day to day shaped me in ways that I am still discovering.

Jack showed me that there was actually a sense of pleasure to be felt in the eye-reddening experience of building a database: along the way, victories were won in uncovering data from a particularly obscure location or environmental setting, or even in typing all of the data into the computer for analysis. I remember that when we were in the throes of completing the genus-level database for our onshore-offshore work, we happened to be taking our Spring Break departmental field trip that year to the Florida Keys. These were in the days before one could hope to do a computer look-up of higher taxonomic designations for genera: it had to be done manually by searching appropriate references. So, at Jack's suggestion, we took all of our data forms and several volumes of the Treatise along with us, to fruitfully spend the long van ride there and back looking up and filling in the class and ordinal designations for most of the genera on our compiled faunal lists. In doing this, we developed a certain rhythm that actually made it fun, although I would not claim that others in the van were begging to help us out.

That field trip provided a look at the breadth of Jack's geological skills. While we transcribed information and Jack talked about the impending data analyses inside the van, he reveled in the field when we were outside. Jack's expertise with the Cambrian is well-known, but, on that trip, I was impressed both by his knowledge of modern tropical settings and his sheer joy at plodding through the mud of Florida Bay and snorkeling through the mangrove roots and reef tract.

But it would be futile to pretend that Jack's first research love was not data compilation and analysis. He was a terrific computer programmer, although it did take him awhile to adjust to a world without keypunched computer cards. He often pointed out to me inefficiencies in my own code, and he wrote programs for multivariate analyses that several of us still use. Jack loved the thrill of the hunt, especially the giddy feeling that accompanies the crunching of a hard-won dataset for the first time. Sometimes, when a new database of mine is ready for analysis, I have trouble leaving the computer for more than a few minutes during lengthy sessions because I cannot wait to get the answer. I blame Jack for this addiction. Whenever I handed him a new ream of fan-fold output, he would immediately whip out his Model-T mechanical pencil - the kind with the fat lead that had to be turned to advance the point - and start writing all over the output, demarcating a cluster on a dendrogram here, circling the samples with particularly high loadings on Axis 1 of a factor analysis there. He would simultaneously distill whatever useful information there was to be gleaned from the output and plan the next round of analyses.

Just as importantly, in the courses that he offered, Jack provided several generations of students with the proper tools to conduct multivariate data analyses. Jack was never content to provide a mere schematic overview of how a particular technique worked; he wanted to be sure that we understood how the peculiarities of individual techniques could affect analytical outcomes. Thus, he insisted on teaching the nuts and bolts, right down to the derivation of eigenvectors and eigenvalues. I suspect that this approach was nearly unique at the time among quantitative methods courses offered in any paleontology program, but this is not the case anymore, because several of Jack's students now do the same.

Jack was also a consummate editor. From the very first time that I prepared a term paper for him at Rochester, he jumped all over my writing style, even though I was a "journalist." He had a clear vision of what constituted appropriate style for a scientific paper or presentation that he obviously wanted to convey to his students, but it was remarkable that he took the time to attempt to hone my scientific writing skills long before there was any indication that I would actually be needing them. This was another manifestation of Jack's overarching desire to perfect the final product, even in instances when the outside world would almost certainly not notice the difference. While it irritated me to have to go through multiple drafts of just about anything I wrote, I now irritate my students in the same way. When my students get back drafts from me covered in a sea of red, they might not realize that they also have Jack to blame-and thank.

Jack also reminded me by his own example that it was important to never become wrapped up in work to the exclusion of the rest of one's life. He cared deeply about the broader, nonacademic world in which he lived, and he had a particular passion for politics. I remember talking to him on the phone shortly after Harold Washington, the former Mayor of Chicago, passed away suddenly. I knew that Jack was impressed by Washington's overturning of the Chicago political establishment, but his sadness over the mayor's death surprised me. He was reverential in tone when describing his feelings about Washington, and he was depressed and worried about what his passing would mean to the city. Perhaps to work through those feelings he attended the public viewing downtown, waiting several hours on line to pay his respects.

The relationship that I developed with Jack in my years at Rochester and Chicago never really changed, even after I finished my Ph.D. and joined the faculty at Cincinnati. Its permanence and importance to me crystallized during a day that we spent together in the Bay Area of California some five years ago, prior to the start of a NASA Exobiology meeting. As we hopped among the tide pools at Half Moon Bay and drove at high speeds over the hills of San Francisco, Jack listened patiently as I talked about so many things that were on my mind and offered advice that I needed badly at that moment. On that day, I realized that any desire that I had to get beyond the advisor/student relationshipto be viewed by Jack as some sort of co-equal-was outweighed by a need for Jack to always be my mentor.

During the spring of 1982-my first academic year in Chicago-Jack and I were driving together to Purdue University for the North-Central GSA meeting, where he was chairing the $\mathrm{Pa}$ leontological Society symposium that year. Somehow, we got into a discussion about how to most effectively produce a major scientific advance, and I remember that Jack stressed the importance of not jumping too far out in front of the rest of the field. Rather, when introducing a novel approach, he suggested that one has to have a sense of what the field is ready for and can realistically assimilate, so that the new approach would, in effect, carry the field along with it. This struck me as a reasonable observation, but, at that moment, I did not appreciate that Jack was speaking from first-hand experience.

A couple of months later, Jack sent me to California to give a talk at a regional AAAS symposium, the presentations from which would later be written up in Jim Valentine's edited volume, Phanerozoic Diversity Patterns: Profiles in Macroevolution. I have no idea why Jack asked me to give our joint paper. He was the clear intellectual force behind our collaboration and, as a rookie, I knew 
that I would not represent him very well. But I was grateful for the opportunity, and it was quite an experience. As I listened to speaker after speaker talk about some aspect of Phanerozoic diversity, I soon realized that the entire symposium had been seeded by Jack's work over the previous few years. The meeting, in fact, was really about him.

One of the things that I really like about our profession-actually, I suppose it is true of any profession-is that you can see the personalities of people emerging in the work that they produce. And so it was with Jack. He was uniquely suited to his role because he had the energy and patience to compile databases that others found daunting, the paleontological expertise to understand and vet the data, the intellectual talent to analyze them with novel approaches, a remarkable understanding of what the field was ready for, and the willingness to endure the resistance of colleagues who had a difficult time adjusting to the changing landscape of paleobiology. With respect to the latter, I witnessed firsthand just how difficult it was for Jack to overcome the inevitable prejudices that come with doing something truly new. Others in his position would have folded, or would have somehow found a way to ignore the withering comments and bickering to which he was subjected. Jack could do neither, and he went out of his way, formally and informally, to engage his critics in meaningful dialogue aimed largely at improving his data and interpretation. It cannot be denied, however, that he sought also to convince them of the value of his approach, and, while he was not always successful, he remained hopeful.

Try to imagine, for a moment, an intellectual landscape that did not include logistic modeling of Phanerozoic diversification, the three Evolutionary Faunas, onshore-offshore patterns of faunal diversification, and periodicity of mass extinctions. Further, consider the prospect of a world without the remarkable array of related research that Jack's work so clearly fueled. It would be a very boring world indeed.

ARNOLD I. MiLleR Department of Geology University of Cincinnati Cincinnati, OH 45221-0013 